Scientia Agricola

http://dx.doi.org/10.1590/1678-992X-2015-0425

\title{
Temporal progress and spatial patterns of quiescent diseases in guava influenced by sanitation practices
}

\author{
Ivan Herman Fischer ${ }^{1 *}$, Ana Raquel Soares-Colletti ${ }^{2}$, Maria Cecília de Arruda Palharini' ${ }^{1}$, Marise Cagnin Martins Parisi ${ }^{3}$, Lilian \\ Amorim $^{2}$
}

\author{
${ }^{1}$ Agency Paulista Agribusiness Technology Regional Midwest \\ Pole, Av. Rodrigues Alves, 40-40 - 17030-000 - Bauru, \\ $\mathrm{SP}$ - Brazil. \\ 2University of São Paulo/ESALQ - Dept. of Plant Pathology \\ and Nematology, Av. Pádua Dias, 11, C.P. 09 - 13418-900 \\ - Piracicaba, SP - Brazil. \\ ${ }^{3}$ Agency Paulista Agribusiness Technology Regional Center \\ South Pole, Rod. SP 127, km 30, C.P. 28 - 13400-970 - \\ Piracicaba, SP - Brazil. \\ *Corresponding author <ihfische@apta.sp.gov.br>
}

Edited by: Emerson Medeiros Del Ponte

Received November 05, 2015

Accepted April 15, 2016
ABSTRACT: Postharvest diseases are a major problem in guava crops as the symptoms normally appear during fruit ripening. This study aimed to detect and characterize the temporal dynamics and spatial patterns of the most important guava diseases in orchards with and without removal of crop residues as a sanitation practice. The experiment was conducted in an orchard of 'Pedro Sato' guavas, over two consecutive seasons, and data were collected from the flowering to the fruit ripening stage. In immature guavas treated with paraquat and ethrel, Colletotrichum spp. was detected from the $5^{\text {th }}$ day of incubation. Anthracnose was detected in flowers at incidences higher than $50 \%$ and black spot in fruit larger than $5.5 \mathrm{~cm}$ in length. The monomolecular and the exponential models provided the best fit to anthracnose and black spot incidence progress curve data, respectively. Both diseases showed a predominantly random spatial pattern in the orchard. The removal of crop residues reduced the rate of disease progress in at least one season, and was effective in reducing the areas under the quiescent disease progress curves (AUDPC) of anthracnose. Anthracnose incidence increased from 57 to $96 \%$ and black spot from 1 to 48 $\%$, respectively, at fruit maturation levels 1 and 3 . A negative correlation was found between disease incidence and the color of the fruit skin $\left({ }^{\circ} \mathrm{h}\right)$. Fruit harvested during the later maturation stages showed higher incidence of the diseases. Due to the wide distribution and early infection of quiescent diseases, starting at flowering, preventive management should consider disease monitoring and removal of crop residues.

Keywords: Colletotrichum, Guignardia, Psidium guajava, postharvest fruit rot

\section{Introduction}

Guava is a highly perishable fruit and is, therefore, more susceptible to postharvest diseases. Once the skin of guava becomes edible, the presence of pathogenic injuries, even a small spot, can compromise fruit quality and make the product unfit for marketing. Such damage can occur not only during harvesting but subsequently, such as in packing houses, and at the grocery wholesaler, retailer and consumer stages. The major postharvest diseases affecting guava are anthracnose, caused by Colletotrichum spp., and black spot caused by Guignardia psidii Ullasa and Rawal (Fischer et al., 2011).

Anthracnose and black spot are defined as quiescent diseases because the pathogens infect the fruit before harvest and remain latent until maturation when physical and physiological changes in the fruit favor pathogen development (Prusky and Lichter, 2007). Methods for detecting quiescent infection of Botryosphaeria dothidea (Moug.) Ces. \& De Not. in apples (ValdebenitoSanhueza et al., 2005) and Colletotrichum sp. in mangos (Paramasivan et al., 2009) already exist. For example, immature fruits are immersed in a paraquat solution that generates free radicals which induce lipid peroxidation and loss of membrane integrity (Dodge, 1971). Thus, senescence is induced in herbicide-treated fruit and the symptoms are expressed.

Colletotrichum spp. survives in mummified fruit on trees or on the ground and in infected twigs and branch- es. The spores are dispersed by rain splashing combined with wind exposure (Singh, 2000). Spore germination and appressorium formation of G. psidii increase as the fruit ages (Escanferla et al., 2009). Nevertheless, knowledge of temporal and spatial analysis of guava diseases is limited but has the potential to provide important information for disease management. The analysis of these patterns may allow inferences about the influence of wind or rain in the dissemination of pathogens, and can provide information on sources of inocula to predict disease levels (Benson et al., 2006).

Little is known about the field epidemiology of guava diseases and the importance of early disease detection in disease management. This study aimed to (i) establish a method for detecting quiescent infections in guavas; (ii) quantify the incidence of postharvest diseases and (iii) characterize their temporal dynamics and spatial patterns in managed and unmanaged orchards by removal of crop residues.

\section{Materials and Methods}

\section{Disease detection in immature fruit}

Immature small $(2 \mathrm{~cm})$ fruit of 'Pedro Sato' guavas were randomly collected from 50 trees (five rows of ten plants each) in an 8-year-old commercial orchard located

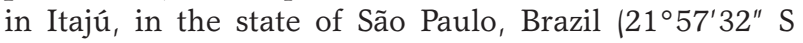
and $\left.48^{\circ} 48^{\prime} 25^{\prime \prime} \mathrm{W}\right)$, with a historical record of anthracnose. Fruit were surface-disinfested with $\mathrm{NaOCl}\left(5 \mathrm{~g} \mathrm{~L}^{-1}\right)$ 
for $5 \mathrm{~min}$ and washed in running water. To express the symptoms, fruit received different treatments by immersion for $1 \mathrm{~min}$ in: (i) paraquat $\left(3 \mathrm{~g} \mathrm{~L}^{-1}\right)$ (Northover and Cerkauskas, 1994); (ii) ethrel $\left(0.1 \mathrm{~g} \mathrm{~L}^{-1}\right)$ (ValdebenitoSanhueza et al., 2005); (iii) urea $\left(50 \mathrm{~g} \mathrm{~L}^{-1}\right)$ (ValdebenitoSanhueza et al., 2005); or water. Afterwards, the fruits were washed for $3 \mathrm{~min}$ under running water. The fruits were placed in plastic pocket trays individually and stored under light at $25{ }^{\circ} \mathrm{C}$ and $80-85 \%$ relative humidity (RH). The experimental design was completely randomized with five replicates per treatment and each replicate was represented by ten fruits. The experiment was repeated once. The best treatment allowing for the quickest detection was used in the field experiments.

Visible symptoms on fruit were assessed daily for 10 days. The Anova assumptions of normality and homoscedasticity were verified and data from two experiments were combined for analysis. A linear mixed effect model was fitted to the logit-transformed disease incidence progress data. The $\mathrm{R}$ software (R Core Team, 2015) and the function "lmer" from "lme4" package (Bates et al., 2015) were used for analysis.

Fifty isolates of Colletotrichum spp. representing 50 plants in a plot as well as four isolates of $L$. theobromae were obtained from immature fruit by direct isolation on potato-dextrose-agar (PDA). Pathogenicity was confirmed by inoculation of fruit at harvest.

\section{Temporal progress and spatial distribution of qui- escent diseases}

Fifteen temporal evaluations of guava quiescent diseases were performed on 50 plants from two plots of 'Pedro Sato' guava orchard located in Itajú, for two harvesting seasons as follows: the first from 29 Sept 2009 to 18 Feb 2010 and the second from 19 July 2010 to 12 Nov 2010. Weather information was recorded in a station located $40 \mathrm{~km}$ from the orchard. For 143 days in the first season, accumulated precipitation was $1,069.0 \mathrm{~mm}$, the average maximum temperature was $31.0^{\circ} \mathrm{C}$ and the average minimum temperature was $17.9{ }^{\circ} \mathrm{C}$. In the 117 days of the second crop season, the accumulated precipitation was $233.6 \mathrm{~mm}$, the average maximum temperature was $28.8^{\circ} \mathrm{C}$ and the average minimum temperature $15.6{ }^{\circ} \mathrm{C}$.

Crop residues (stems, leaves and fruit) lying on the ground were removed in one of the plots one month before the start of sampling to evaluate its importance as a source of inoculum of quiescent diseases. During the fruiting period, fallen fruit was removed on a monthly basis to reduce the inoculum amount. Once a week, two flowers/fruits per guava tree were collected from 50 plants in each plot. Sampling started during the flowering period and continued until harvesting, totaling 15 samples in each plot. Three commercial maturation stages were recorded according to skin color $(1=$ dark green, 2 = light green and 3 = yellow-green).

During the first season, the flowering and sampling period differed by one month between plots be- cause pruning was conducted at different times in the plots. Flowers and immature fruit were disinfected with $\mathrm{NaOCl}\left(5 \mathrm{~g} \mathrm{~L}^{-1}\right)$ for $5 \mathrm{~min}$, washed in running water, immersed for $1 \mathrm{~min}$ in paraquat $\left(3 \mathrm{~g} \mathrm{~L}^{-1}\right)$ and washed for 3 min under running water. The flowers and immature fruit were subsequently incubated under light at $25^{\circ} \mathrm{C}$ and 80-85 \% RH. Disease incidence was assessed 10 days later, except for mature fruit that were assessed every 2 days for 10 days. Different population dynamic models including monomolecular $\left(y=1-\left(1-y_{0}\right) \exp (-r t)\right)$, logistic $y=1 /\left[1+\exp \left\{-\ln y_{0} /\left(1-y_{0}\right)+r t\right\}\right]$, exponential $(y=$ $\left.y_{0} \exp (r t)\right)$ and Gompertz $\left(y=\exp \left(\ln y_{0} \exp (-r t)\right)\right.$, where $y$ is the rate of disease incidence, $y_{0}$ the initial inoculum, $r$ the disease progress rate and $t$ the time /Campbell and Madden, 1990), were fitted to incidence progress data for anthracnose and black spot recorded using nonlinear regression models in the Statistica 6.0 software (Statsoft, Tulsa, OK, EUA). The best-fitted model was chosen based on the coefficient of determination $\left(R^{2}\right)$ and distribution of residuals. The parameters $\left(y_{0}\right.$ - initial inoculum and $r$ - disease progress rate) of the models fitted to data from each treatment (with and without crop residues) were compared for both years based on the t-test (Campbell and Madden, 1990). The areas under the quiescent disease progress curves (AUDPC) were calculated by trapezoidal integration (Berger, 1988) and the data for each disease were analyzed in a $2 \times 2$ factorial design, comparing the two harvesting seasons and with and without crop residues, using the Tukey's test at a 5 $\%$ probability level, considering each row of ten plants as a replication.

The spatial pattern of diseased trees (based on fruit symptoms of black spot and anthracnose) was evaluated weekly in 40 plants in the plot during the same period of the temporal progress evaluation. The plots were divided into quadrats of $2 \times 2$ trees. The spatial pattern was determined based on the dispersion index $D=V_{\text {obs }} / V_{b i n^{\prime}}$ where $V_{\text {obs }}=\left[(X i-n p)^{2} / n^{2}(N-1)\right]$ and $V_{\text {bin }}=p(1-p) / n$, and where $V_{\text {obs }}$ is the observed variance, $V_{\text {bin }}$ is the binomial variance, $X i$ represents the number of diseased plants per quadrat, $n$ the number of plants per quadrat, $N$ the total number of quadrats and $p$ is the probability of a plant having diseased fruit (Hughes et al., 1996). The value of $D$ was tested against the $\chi^{2}$ using $p \leq 0.05$ as the significance level. The binary Taylor's Power Law model was fitted to all weekly data of the two crop seasons, but separately for plots with and without crop residues, as follows: $\log \left(V_{\text {obs }}\right)=A+b^{*} \log \left(V_{\text {bin }}\right)$, where $A$ and $b$ are parameters (Madden and Hughes, 1995) calculated by linear regression. According to this equation, where $b=1$ and $a=0$, the distribution is random and where $a>0$ and $b>1$, the distribution is aggregated. The hypotheses were tested at a $5 \%$ probability.

\section{Incidence of quiescent diseases at postharvest}

The means of incidence of each disease at three maturation stages of the fruit were compared using Tukey's test at the $5 \%$ probability level, considering 
each row of ten plants as a replication. Different models $\left[y=1-b_{2} \exp (-r t) ; y=b_{1}\left(1-b_{2} \exp (-r t)\right]\right.$, where $y$ is the incidence of disease in proportion, $b_{1}$ the maximum asymptote, $b_{2}$ the parameter related to the initial inoculum of disease, $r$ the rate of disease progression and $t$ the time in days after the beginning of storage, were fitted to the anthracnose and black spot progress curves.

\section{Detection of Colletotrichum spp. in tree bark}

In a separate plot without crop residues, Colletotrichum spp. occurrence was evaluated on guava tree trunks 1 month after the end of harvesting (03/2010) and during the flowering of the following season (07/2010). The pathogen was detected by the direct transfer of 36 small fragments of bark (trunk) per plant on potato dextrose agar (PDA) for five plants randomly chosen in the field. The effect of surface disinfestation on bark with $\mathrm{NaOCl}\left(5 \mathrm{~g} \mathrm{~L}^{-1}\right)$ for 1 min was not significantly different $(p \leq 0.05)$ from that with absence of disinfestation in isolation of Colletotrichum spp. in the preliminary test. After 5 days of plate incubation at $25^{\circ} \mathrm{C}$, Colletotrichum spp. isolates were transferred and purified in PDA. Differences in mean isolation frequency between the five sampled plants were compared by the Tukey's test, at the $5 \%$ probability level. Pathogenicity was confirmed by inoculation with mycelial discs of fungus isolates in guava fruit (Fischer et al., 2011).

\section{Physicochemical fruit traits and diseases}

In addition to disease detection, fruits were sampled at three maturation stages $(1,2$ and 3$)$ to characterize the following physicochemical parameters: a) skin color, determined by a colorimeter with readings in the equatorial region of the fruit and the results were expressed as hue angles $\left({ }^{\circ} \mathrm{h}\right) ;$ b) flesh firmness, determined by a digital penetrometer with an $8 \mathrm{~mm}$ tip with readings in the equatorial region of the fruit and the results were expressed in Newtons $(\mathrm{N})$; c) soluble solids content, determined in a digital refractometer and the results were expressed in ${ }^{\circ}$ Brix; d) acidity, determined by titration with $\mathrm{NaOH}$ and the results expressed as $\mathrm{g} \mathrm{L}^{-1}$ citric acid; and e) ascorbic acid content, determined by titration with DCFI $(2,6$ dichlorophenol indophenol sodium salt) and the results were expressed in $\mathrm{mg} 100 \mathrm{~g}^{-1}$ (AOAC, 2005). The experimental design was completely randomized with five replicates of six fruits per treatment. The physicochemical parameters in each fruit maturation stage for the plots with and without crop residues were compared by the Tukey's test $(p \leq 0.05)$. The physicochemical parameters were correlated with disease incidence using the Spearman correlation $(p \leq 0.05)$.

\section{Results and Discussion}

\author{
Detection of latent pathogen infections in imma- \\ ture guavas \\ Colletotrichum conidia were observed at the $5^{\text {th }}$ day \\ of incubation of guava fruit immersed in paraquat and
}

ethrel solution, at higher incidence compared with urea and water on the $6^{\text {th }}$ and $7^{\text {th }}$ day of incubation onward. Significant interaction between treatment and day of incubation was observed $(p \leq 0.05)$. Colletotrichum was detected in $96 \%$ of fruit treated with paraquat and ethrel on the $7^{\text {th }}$ day. In the urea and water treatment, incidence was $93 \%$ only at the $9^{\text {th }}$ day (Figure 1). Lasiodiplodia theobromae Pat. Griffon \& Maubl was also detected, but at a low incidence $(2 \%)$.

Based on these results, paraquat or ethrel could be recommended for the quick and reliable detection of latent Colletotrichum spp. infections in immature guava fruit. The effect of ethrel may be associated with the stimulation of ethylene production in fruit and thus the activation of quiescent $C$. gloeosporioides (Penz.) Penz \& Sacc. infections, as previously reported for avocados (Prusky et al., 1996). When treating mango fruit with paraquat, anthracnose symptoms were anticipated in 4-5 days, which assisted in decisions regarding storage time and whether to export or send the fruit to the domestic market in India (Paramasivan et al., 2009).

\section{Temporal progress and spatial distribution of qui- escent diseases}

Anthracnose was the main disease in 'Pedro Sato' guavas (Table 1) with virtually $100 \%$ incidence in immature small fruit $(3 \mathrm{~cm})$ during the first season (Figure 2A). According to Moraes et al. (2015), there is no difference in conidial germination and appressorium formation of $C$. gloeosporioides in guavas at different ages. Fifty percent of Colletotrichum spp. infection was observed during the flower opening stage. The incidence of major postharvest diseases was lower during the second crop season (Figure 2B), possibly because of less favorable weather conditions with lower temperatures and pre-

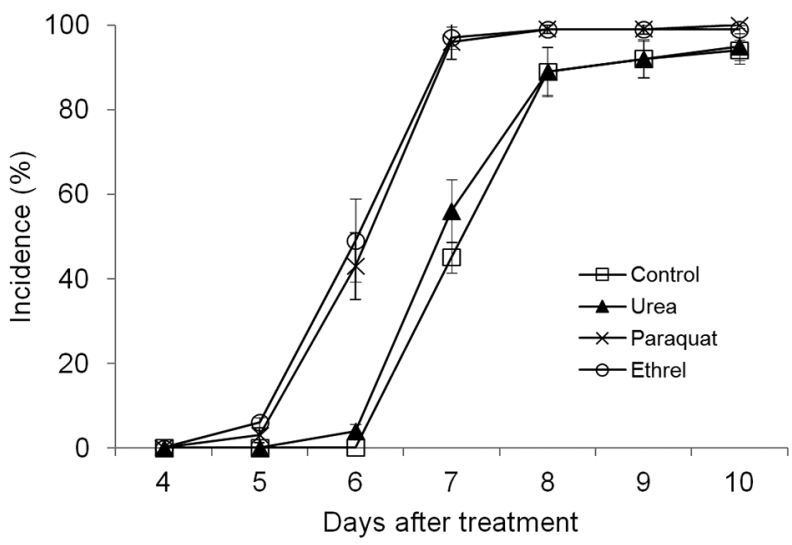

Figure 1 - Incidence (\%) of anthracnose in immature fruit (2 cm long) of 'Pedro Sato' guavas for different postharvest treatments. The disease assessment was performed for 10 days of storage at $25{ }^{\circ} \mathrm{C}$ and $80-85 \%$ relative humidity. Averages of two replicates with 50 fruit each. Vertical bars represent the standard deviation of the means. 
Table 1 - Area under the disease progress curve (AUDPC) calculated from 15 weekly evaluations (flowering to harvest) of postharvest diseases in 'Pedro Sato' guavas grown in plots with and without crop residues after 10 days of storage at $25{ }^{\circ} \mathrm{C}$ and $80-85 \%$ relative humidity. Averages for two crop seasons (2009/10 and 2010).

\begin{tabular}{lcc}
\hline \multirow{2}{*}{ Diseases } & \multicolumn{2}{c}{ AUDPC } \\
\cline { 2 - 3 } & Plot without crop residues & Plot with crop residues \\
\hline Anthracnose & $9,143.8 \mathrm{a}^{*}$ & $9,534.3 \mathrm{~b}$ \\
Black spot & $666.5 \mathrm{a}$ & $772.8 \mathrm{a}$ \\
Pestalotia rot & $297.5 \mathrm{a}$ & $714.8 \mathrm{~b}$ \\
Phomopsis rot & $238.8 \mathrm{a}$ & $323.8 \mathrm{~b}$ \\
Fusicocum rot & $208.5 \mathrm{a}$ & $329.8 \mathrm{~b}$ \\
Lasiodiplodia rot & $25.0 \mathrm{a}$ & $40.0 \mathrm{a}$ \\
\hline
\end{tabular}

*Values followed by different letters in each row are significantly different by Tukey's test $(p \leq 0.05)$.

cipitation. The optimum temperature for infection by $C$. gloeosporioides lies between 22 and $25{ }^{\circ} \mathrm{C}$ (Piccinin et al., 2005). The optimal temperature for germination and formation of $G$. psidii appressoria ranges between 25 and $30{ }^{\circ} \mathrm{C}$ (Escanferla et al., 2009).

Black spot in guava, found in fruit at $5.5 \mathrm{~cm}$ in length, was observed at high intensity in both plots when fruit reached maturation (Figure 2A). The high incidence of black spot and anthracnose is related to the ability of the pathogens to infect unripe and uninjured fruit (Picinnin et al., 2005; Martins et al., 2007). Other postharvest diseases detected in both plots were pestalotia, phomopsis, fusicocum and lasiodiplodia rots (Table 1). Mucor and dothiorella rots were found at low incidences, with AUDPC values below 5.4. Since no interaction was observed ( $p>0.05)$ between harvesting seasons and crop residues, the average of harvesting seasons is presented in Table 1. Except for black spot and lasiodiplodia rot, crop residue removal was effective in reducing the incidence of diseases.

The monomolecular model provided the best fit to the anthracnose progress curve in the plots without crop residues $\left(b_{2}=1.84 ; r=0.05, R^{2}=0.78\right)$ and with crop residues $\left(b_{2}=0.27 ; r=0.07, R^{2}=0.87\right)$ for the first sampled crop season (Figure 2A). The monomolecular model most frequently describes the progress of monocyclic diseases. However, it also describes the progress of quiescent diseases, regardless of their designation as monocyclic or polycyclic (Bergamin Filho and Amorim, 2002). The monomolecular model showed a good fit to the temporal progress of apple leaf spot incidence caused by C. gloeosporioides (Guerra et al., 2012) and of witches' broom observed in cocoa fruit (Alves et al., 2006). In the second crop season, none of the models tested was fitted to the anthracnose progress curves (Figure 2B).

The exponential model presented the best fit to the progress curve for black spot in the crops with $\left(1^{\text {st }}\right.$ year: $y_{0}=0.0003 ; r=0.072$; and $R^{2}=0.97$ and $2^{\text {nd }}$ year: $y_{\mathrm{o}}=0.000003 ; r=0.098$; and $\left.R^{2}=0.98\right)$ and without

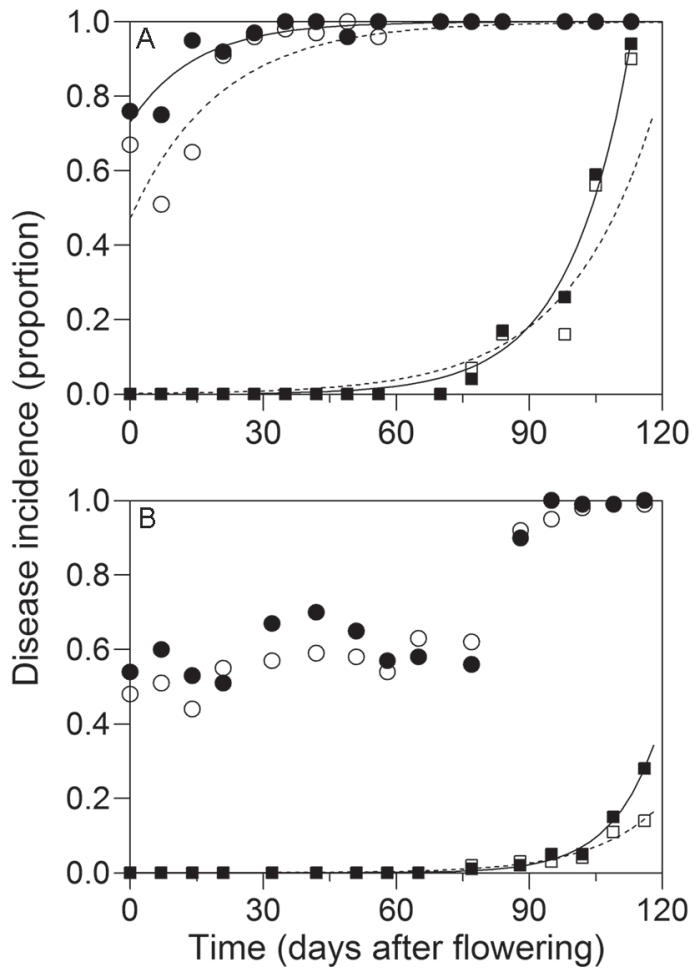

Figure 2 - Progress incidence (proportion) of anthracnose (circles) and black spot (squares) for different developmental stages of 'Pedro Sato' guavas (flower to commercial fruit) from the plot without crop residues (empty) and with crop residues (full) after 10 days of storage at $25{ }^{\circ} \mathrm{C}$ and $80-85 \%$ relative humidity. Points represent disease incidence in proportion and lines fit with the monomolecular model $\left(y=1-y_{0} \exp (-r t)\right)$ (anthracnose) and exponential $\left(y=y_{0} \exp (r t)\right)$ (black spot), where $y$ is the disease incidence in proportion, $y_{0}$ is the disease initial inoculum, $r$ is the rate of disease progression and $t$ is the time in days. Data from the first year of sampling (29/09/2009 to $18 / 02 / 2010)(A)$ and the second year of sampling (19/07/2010 to $12 / 11 / 2010)(B)$.

residues $\left(1^{\text {st }}\right.$ year: $y_{0}=0.0007 ; r=0.050 ;$ and $R^{2}=0.93$ and $2^{\text {nd }}$ year: $y_{0}=0.00008 ; r=0.065$; and $R^{2}=0.93$ ) (Figure 2A and B). In citrus, the monomolecular model best fitted the progress curves of black spot caused by Guignardia citricarpa Kiely (Spósito et al., 2004) because of the long latent period of the disease on fruit. In the case of guava black spot, the latent period and the inoculum source of the disease are unknown. The exponential shape of the progress curve could be related to the resistance of young fruit to pathogen infection. The infection rate of $G$. psidii gradually increases with fruit development. Spore germination was $11 \%$ and appressorium formation was $2 \%$ in 10 day old fruit. In 110-day old fruit, spore germination and appressoria formation was 43 and $23 \%$, respectively (Escanferla et al., 2009). It is possible that exogenous stimuli in ripe fruit influence the germination process of G. psidii conidia (Escanferla et al., 2009). 
The progress rates of anthracnose and black spot were higher when crop residues were present $(p \leq 0.05)$, which suggests that both pathogens can survive in these residues that perpetuate within-field inoculum in the absence of flowers or fruit. The mucilage around the conidia of Colletotrichum sp. allows for pathogen survival for long periods in plant debris. In addition, Colletotrichum spp. is known to survive in several species of wild and cultivated plants (Silva and Michereff, 2013). The high disease incidence at the beginning of the season is probably related to the high survival capacity of this pathogen. Moreover, as a perennial crop, guava trees remain in the field for many years enabling a continued increase in the incidence of pathogens that survive in crop residues. Therefore, crop residues may be sources of local inocula besides other planting areas. Further studies are recommended, preferably with evaluations performed over a longer period. According to Piccinin et al. (2005), among the measures to control postharvest diseases of guava, especially quiescent diseases, pruning diseased branches, cleaning the orchard and immediately burning all crop residues are of paramount importance to reduce the amount of inocula in the field.

A modified Taylor's Power Law provided a good fit for the relationship between the log of the two variances for black spot in both plots without $\left(R^{2}=0.82\right.$, Figure $3 \mathrm{~A})$ and with $\left(R^{2}=0.59\right.$, Figure $\left.3 \mathrm{~B}\right)$ crop residues. For anthracnose, this Taylor's Power Law fitted well the data from plots with crop residues only $\left(R^{2}=0.94\right.$, Figure $3 \mathrm{C})$. The hypothesis that $b=1$ was not rejected $(p>$ $0.05)$ based on the $t$-test, suggesting a random distribution of trees with black spot and anthracnose. In most assessments, the dispersion index $(D)$ did not differ from $1(p \leq 0.05)$, suggesting a random distribution of the disease. An exception was the assessment of 22 Dec 2009 for black spot in the plot with crop residues, where $D=$ 2.59, indicating aggregation (Table 2).

The causal agent of black spot is known to produce ascospores and conidia. Spore traps in the field detect only G. psidii ascospores. Phyllosticta psidiicola (Petrak) van der Aa conidia are not found, suggesting that ascospores might act as the main inoculum (Lin et al., 2003). In the G. citricarpa-citrus pathosystem, ascospores that form in decaying leaves on the ground are spread over short and long distances by the wind (Spósito et al., 2007), which could explain the random distribution pattern of black spot in guava or extensive distribution of the inoculum in the field with all trees acting as a source of pathogen survival. Unlike our findings for guava black spot, diseased citrus plant exhibited a clustered pattern, regardless of disease incidence, indicating the high importance of inocula dispersal over short distances and suggesting the involvement of conidia in the disease increase under field conditions in the state of São Paulo (Spósito et al., 2007).

The most likely explanation for the high initial incidence of anthracnose at flowering is that the inoculum was already present and homogeneously distributed in

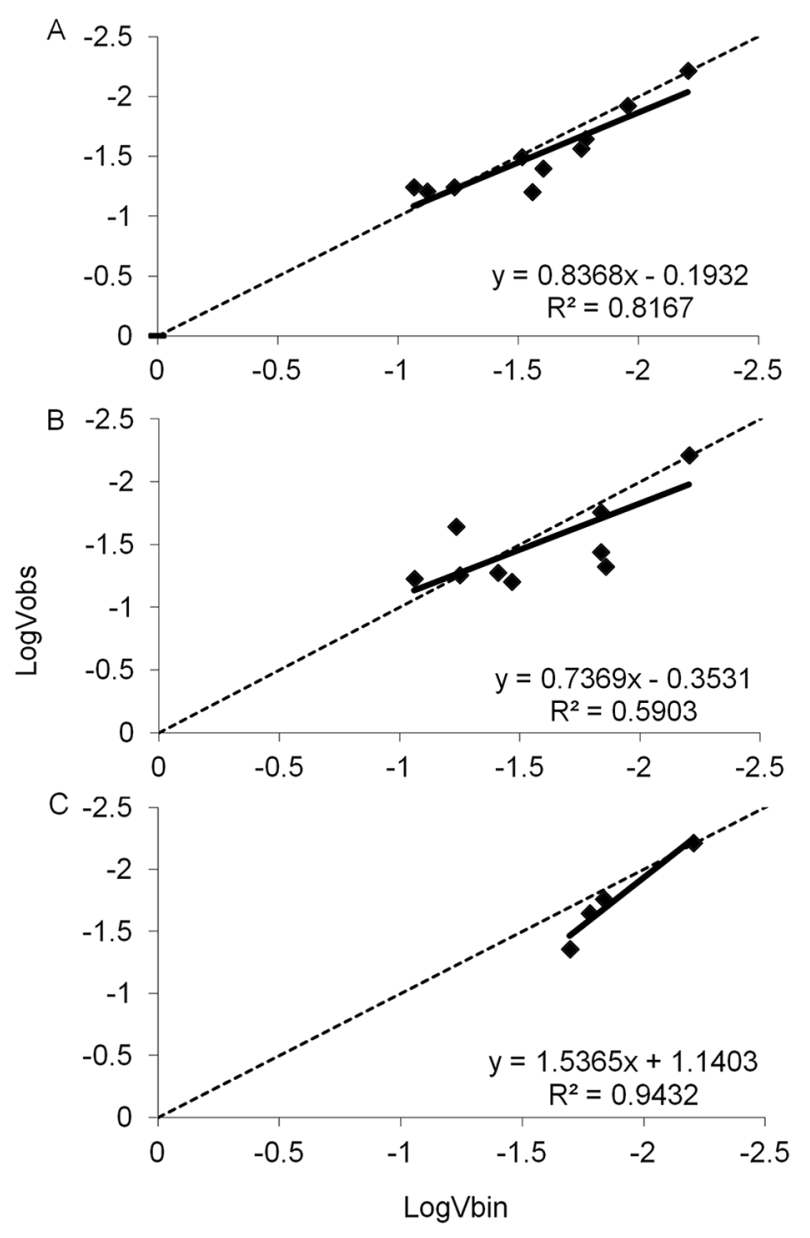

Figure 3 - Relationship between the logarithm of the expected binomial variance and logarithm of the variance observed in incidence evaluations of 'Pedro Sato' guava plants with black spot symptoms in without (A) and with crop residues (B) plots and anthracnose in a with crop residues plot (C) for a quadrat size of 2 $\times 2$ in Itajú-SP, with harvests in 2009 and 2010 .

the area. Further studies are necessary preferably in younger trees with lower incidences of anthracnose to verify a possible clustering of diseased trees. According to Timmer et al. (1994), mechanisms of C. acutatum J.H. Simmonds dispersal over long distances are not clear. Thus, it is not possible to explain how a disease caused by Colletotrichum occurs suddenly and causes losses of up to $100 \%$ in citrus. In São Paulo, the postbloom fruit drop of citrus had a variable spatial pattern, which was initially random and then, it became moderately aggregated, suggesting the existence of other dispersal mechanisms besides rain with winds (Silva Júnior et al., 2014).

\section{Disease incidence at postharvest}

The monomolecular model showed the best fit to the anthracnose and black spot progress curves after harvest for all three maturation stages (Figure 4A, B, C 
Table 2 - Dispersion index (D) of the incidence of black spot symptoms during weekly evaluations in 'Pedro Sato' guava plants in without and with crop residues plots and of anthracnose in with crop residues plot. The quadrat size was $2 \times 2$ in Itajú-SP, with harvests in 2009 and 2010.

\begin{tabular}{|c|c|c|c|}
\hline \multirow{3}{*}{ Date } & \multicolumn{3}{|c|}{ Dispersion index (D) } \\
\hline & \multicolumn{2}{|c|}{ Black spot } & \multirow{2}{*}{$\begin{array}{c}\text { Anthracnose } \\
\text { with crop } \\
\text { residues }\end{array}$} \\
\hline & $\begin{array}{l}\text { with crop } \\
\text { residues }\end{array}$ & $\begin{array}{l}\text { without crop } \\
\text { residues }\end{array}$ & \\
\hline 29 Sept 2009 & $-{ }^{*}$ & - & 0.74 \\
\hline 22 Dec 2009 & $2.59^{* *}$ & - & - \\
\hline 05 Jan 2010 & 1.48 & - & - \\
\hline $12 \operatorname{Jan} 2010$ & 1.03 & - & - \\
\hline 20 Jan 2010 & 1.03 & 0.63 & - \\
\hline 26 Jan 2010 & - & 1.51 & - \\
\hline 02 Feb 2010 & - & 1.21 & - \\
\hline 18 Feb 2010 & - & 1.03 & - \\
\hline 19 July 2010 & - & - & 0.46 \\
\hline 26 July 2010 & - & - & 0.84 \\
\hline 02 Aug 2010 & - & - & 1.03 \\
\hline 04 Oct 2010 & 1.03 & 0.94 & - \\
\hline 15 Oct 2010 & 0.84 & 0.74 & - \\
\hline 22 Oct 2010 & 0.40 & 0.96 & - \\
\hline 29 Oct 2010 & 0.30 & 0.62 & - \\
\hline 05 Nov 2010 & 0.55 & 1.02 & - \\
\hline 12 Nov 2010 & 0.74 & 0.44 & - \\
\hline
\end{tabular}

*When disease incidence was zero or when it was close or equal to $100 \%$, the observed variance could not be determined $(-) ;{ }^{* \star} D \neq 1(p \leq 0.05)$. and D). A similar result was observed for anthracnose during fruit development in the first crop season (Figure 2A) and for citrus black spot (Spósito et al., 2004). The monomolecular model presented a good fit also for the guava anthracnose progress curve established in fruit marketed wholesale in Brazil. However, none of the tested models had a good fit for the black spot incidence progress curves (Fischer et al., 2011).

The overall incidence of postharvest diseases, considering the average of the two plots (with and without crop residues) was higher than $50 \%$ in the three ripening stages. On average, anthracnose incidence was 78 $\%$ followed by black spot with $22 \%$ of diseased fruit. Fusicocum, phomopsis, pestalotia, mucor, lasiodiplodia and dothiorella rot incidences were below $3 \%$ and did not differ among themselves ( $p>0.05$ ) (data not shown). Differences in anthracnose and black spot incidences were observed among the three maturation stages. Anthracnose incidences increased from 57 to $96 \%$ of diseased fruit and black spot incidences increased from 1 to $48 \%$ of diseased fruit, respectively, in fruit at maturation levels 1 and 3 (Figure $5 \mathrm{~A}$ and B). 'Pedro Sato' guavas harvested at maturation stage 1 should be commercialized within 6 days. This time is reduced to four and two days if fruit are harvested at stages 2 and 3, mainly because of the occurrence of rots (Azzolini et al., 2004).

Postharvest diseases downgrade fruit for sale and must not exceed $20 \%$ during the fruit shelf life (Paull,

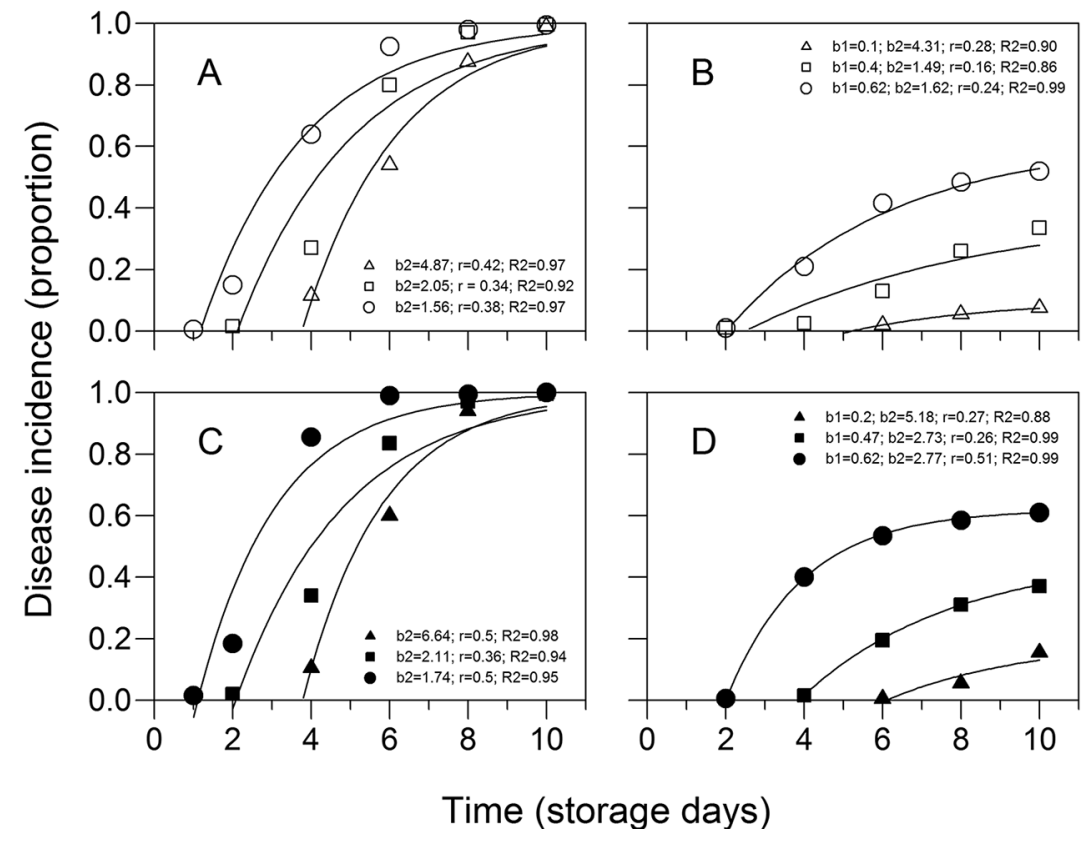

Figure 4 - Progress incidence (proportion) of anthracnose (A and C) and black spot (B and D) in 'Pedro Sato' guavas harvested at three maturation stages, according to skin color $[1=$ dark green (triangles), $2=$ light green (squares) and $3=$ yellow-green (circles)] in plots (area) with (C and D) and without crop residues ( $A$ and B) for 10 days of storage at $25{ }^{\circ} \mathrm{C}$ and 80 to $85 \%$ relative humidity. Averages for 2009 and 2010. Parameters and determination coefficients of regression $\left(R^{2}\right)$ for the models $y=1-b_{2} \exp (-r t)$ (anthracnose) and $y=b_{1}\left(1-b_{2} \exp (-r t)(b l a c k\right.$ spot), where $y$ is the incidence of disease in proportion, $b_{1}$ the maximum asymptote, $b_{2}$ the parameter related to the initial inoculum of disease, $r$ the rate of disease progression and $t$ the time in days after the beginning of storage, which set the progress curves of diseases. 

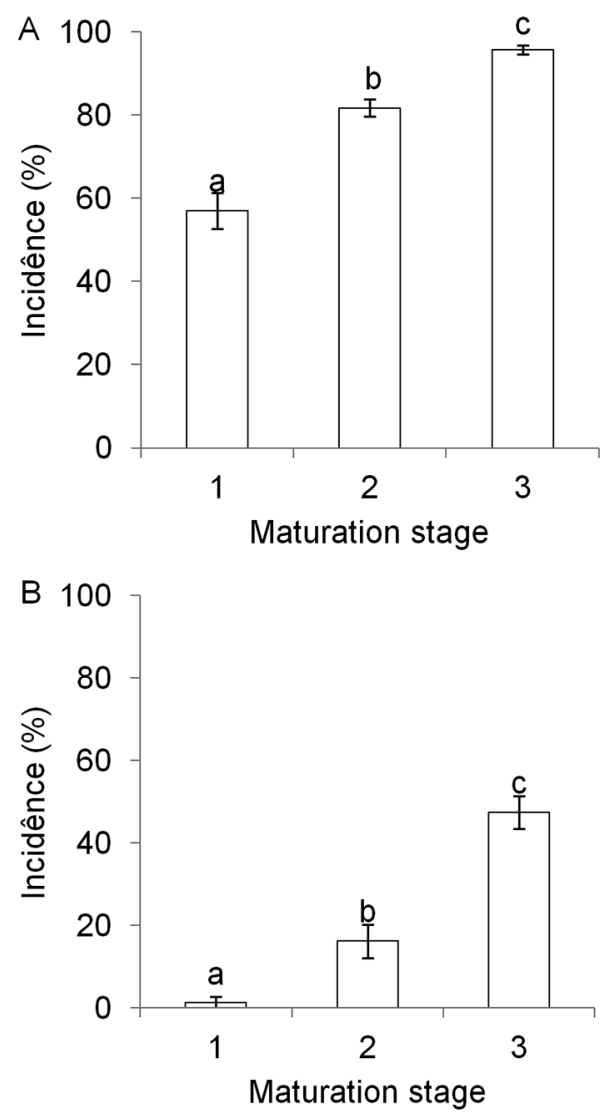

Figure 5 - Incidence of anthracnose (A) and black spot (B) on 'Pedro Sato' guavas harvest at three maturation stages, according to skin color ( 1 = dark green, 2 = light green and 3 = yellow-green), after 6 days of storage at $25^{\circ} \mathrm{C}$ and $80-85 \%$ relative humidity. Averages for two samples of 100 fruit each in 2009 and 2010. Vertical bars represent the standard deviation of the means. Treatments with different letters indicate differences $(p \leq 0.05)$.

1999). However, incidences of postharvest diseases exceeding $40 \%$ in guava have been reported in the state of São Paulo (Fischer et al., 2011). In this study, the marketing period was even lower than that found by Azzolini et al. (2004) because fruit maturation at stage 2 had levels of anthracnose symptoms exceeding $20 \%$ by the $4^{\text {th }}$ day of storage (Figure 4A and C). According to Martins et al. (2007), the high incidence of fruit rot during the summer of each year explains why the fruit is harvested before the maturation point with negative consequences for the final quality of the product, which suggests the necessity to adopt measures for more effective control during the production and postharvest phases.

The results indicate that anthracnose was the most common postharvest disease, confirming findings in the literature (Piccinin et al., 2005; Fischer et al., 2011). After 10 days of storage at $25^{\circ} \mathrm{C}$, the average incidence of black spot and anthracnose reached values above $30 \%$ in guavas marketed in the São Paulo wholesale market (Soares-Colletti et al., 2014). In Taiwan, where black spot causes large losses, the disease reached 80 and $95 \%$ incidences in the Pearl and Crystal cultivars, respectively, after 5 days of fruit storage (Lin et al., 2003).

\section{Detection of Colletotrichum spp. in tree bark}

One month after the end of the first season's harvesting, Colletotrichum spp. was present in $25 \%$ of guava tree trunks and in $14 \%$ of tree trunks during the flowering of the following season. Although there was a decrease in $45 \%$ incidence after the offseason, tree trunks are a possible source of pathogen inoculum for the next crop season. No differences $(p>0.05)$ were observed in isolation frequency among the five plants sampled and pathogenicity of isolates was confirmed in guava fruit.

Relationships between physicochemical characteristics and postharvest diseases for guavas

The physicochemical variables of fruit were similar in both plots (with and without crop residues) of 'Pedro Sato' guavas. Differences in skin color, flesh firmness, acidity and solids-acidity ratio were observed between the three maturation stages (Table 3). Similar results were observed by Azzolini et al. (2004) for 'Pedro Sato' guavas at harvesting.

Flesh firmness of fruit at maturation stage 2 was between 66.72 and $78.56 \mathrm{~N}$ in both plots, averaging $45 \%$ less than that of stage 1 and $49 \%$ greater than that of stage 3 (Table 3). Titratable acidity of fruit decreased as the fruit ripened with average values $7 ; 6$ and $5 \mathrm{~g} \mathrm{~L}^{-1}$ citric acid for maturation stages 1,2 and 3, respectively, in both plots. According to Wills et al. (2007), during ripening, a pronounced decrease in organic acid content is found in most fruits because these compounds are used as substrates during the respiration process. The ratio (solids:acidity) in fruit from plots 1 and 2 increased with advancing maturation stages because of acidity reduction (Table 3).

The soluble solids content of the fruit did not differ $(p>0.05)$ over the three maturation stages (Table 3), which was inconsistent with the results of Azzolini et al. (2004). The total soluble solids (SS), as expressed in ${ }^{\circ} \mathrm{Brix}$, is used as an indirect measurement of sugar content. Generally, sweetness increases with the ripening process because of the accumulation of sugars when the fruit stays on the tree.

Ascorbic acid levels were similar for fruit from the plot with crop residues at stages 2 and 3 and higher $(p \leq 0.05)$ than those in stage 1 . Azzolini et al. (2004) only found differences between stages 1 and 3 with ascorbic acid values of approximately $37 \%$, which were lower than those obtained in this work. For the fruit from the plot without crop residues, ascorbic acid found during stages 1 and 3 did not differ and a lower ascorbic acid content was observed during stage 2 (Table 3).

A negative correlation $(p \leq 0.05)$ was observed between the incidence of anthracnose and skin color $(r=-0.90)$, flesh firmness $(r=-0.85)$ and titratable acidity $(r=-0.71)$ parameters, that is, as these physi- 
Table 3 - Physical-chemical characteristics of 'Pedro Sato' guava harvested at three maturation stages $(1=$ dark green, $2=$ light green and 3 = yellow-green) in plots with and without crop residues. Averages for two seasons (2009/10 and 2010).

\begin{tabular}{|c|c|c|c|c|c|c|}
\hline \multirow{2}{*}{ Physical-chemical characteristics } & \multicolumn{3}{|c|}{ Plot with crop residues } & \multicolumn{3}{|c|}{ Plot without crop residues } \\
\hline & Stage 1 & Stage 2 & Stage 3 & Stage 1 & Stage 2 & Stage 3 \\
\hline Skin color $\left({ }^{\circ} \mathrm{h}\right)$ & $118.13 a^{*}$ & $114.38 \mathrm{~b}$ & $109.40 \mathrm{c}$ & $117.43 \mathrm{a}$ & $114.72 \mathrm{~b}$ & $109.80 \mathrm{c}$ \\
\hline Flesh firmness (N) & $106.31 \mathrm{a}$ & $78.56 b$ & $33.48 c$ & $104.55 \mathrm{a}$ & $66.72 \mathrm{~b}$ & $40.43 c$ \\
\hline Soluble solids ( ${ }^{\circ}$ Brix) & $8.99 \mathrm{~ns}^{* *}$ & 9.05 & 9.05 & $9.34 \mathrm{~ns}$ & 8.94 & 9.33 \\
\hline Acidity (g L $\mathrm{L}^{-1}$ citric acid) & $6.8 \mathrm{a}$ & $5.4 \mathrm{~b}$ & $4.6 \mathrm{c}$ & $7.0 \mathrm{a}$ & $5.7 b$ & $5.2 \mathrm{c}$ \\
\hline Ratio & $13.33 c$ & $16.92 b$ & 19.59 a & $13.42 \mathrm{c}$ & $15.64 \mathrm{~b}$ & $17.82 \mathrm{a}$ \\
\hline Ascorbic acid (mg $100 \mathrm{~g}^{-1}$ ) & $56.39 b$ & $70.85 \mathrm{a}$ & $66.85 \mathrm{a}$ & $70.41 \mathrm{a}$ & $61.91 \mathrm{~b}$ & $71.78 \mathrm{a}$ \\
\hline
\end{tabular}

${ }^{*}$ Means followed by the same letter in the row do not differ in each plot (Tukey's test, $\left.p \leq 0.05\right)$. ${ }^{*}$ ns $=$ not significant $(p \leq 0.05)$.

cochemical parameters decreased with fruit ripening, there was a proportional increase in disease incidence. Several physiological changes that occur during fruit ripening, such as the activation of ethylene biosynthesis, cuticular changes and loosening of cell walls, which is accompanied by a decline in antifungal compounds, led to the occurrence of fruit diseases (Prusky et al., 2013). Associations between the increased disease occurrence with decreasing acidity or increasing soluble solids concentrations have been reported in apples (Sharma and Kaul, 1988) and cherry fruit (Northover and Biggs, 1990) making these parameters useful for identifying periods of fruit susceptibility in the field. Similarly, a negative correlation between the incidence of black spot and skin color $(r=-0.69)$ and a positive correlation between disease incidence and ascorbic acid content $(r=0.60)$ were observed.

Thus, skin color, flesh firmness and titratable acidity parameters for three maturation stages contributed to an understanding of the causes of resistance or susceptibility of guavas to the primary postharvest guava disease and may be considered when planning for a harvesting point aimed to achieve a greater shelf life for this fruit.

\section{Acknowledgements}

The authors wish to the São Paulo State Foundation for Research Support for the financial support to the research project (FAPESP 09/09337-2) and Juan Pablo Edwards Molina for collaboration in the statistical analysis.

\section{References}

Alves, S.A.M.; Pomella, A.W.V.; Aitken, W.M.; Bergamin Filho, A. 2006. Disease progress curves and gradients of witches' broom disease in a cloned cocoa area, in Uruçuca, Bahia. Fitopatologia Brasileira 31: 483-491 (in Portuguese, with abstract in English).

Association of Official Analytical Chemists [AOAC]. 2005. Official Methods of Analysis. 18ed. AOAC, Gaithersburg, MD, USA.

Azzolini, M.; Jacomino, A.P.; Bron, I.U. 2004. Indices to evaluate postharvest quality of guavas under different maturation stages. Pesquisa Agropecuária Brasileira 39: 139-145 (in Portuguese, with abstract in English).
Bates, D.; Maechler, M.; Bolker, B.; Walker, S. 2015. Fitting linear mixed-effects models using lme4. Journal of Statistical Software 67: 1-48.

Benson, D.M.; Grand, L.F.; Vernia, C.S.; Gottwald, T.R. 2006. Temporal and spatial epidemiology of Phytophthora root rot in Fraser fir plantations. Plant Disease 90: 1171-1180.

Bergamin Filho, A.; Amorim, L. 2002. Diseases with a variable incubation period as a function of the host phenology. Fitopatologia Brasileira 27: 561-565 (in Portuguese, with abstract in English).

Berger, R.D. 1988. The analysis of the effects of control measures on the development of epidemics. p. 137-151. In: Kranz, J.; Rotem, J., eds. Experimental techniques in plant disease epidemiology. Springer, Heidelberg, Germany.

Campbell, C.L.; Madden, L.V. 1990. Introduction to Plant Disease Epidemiology. John Wiley, New York, NY, USA.

Dodge, A.D. 1971. The mode of action of bipyridylium herbicides, paraquat and diquat. Endeavour 30: 130-135.

Escanferla, M.E.; Moraes, S.R.G.; Salaroli, R.B.; Massola Júnior, N.S. 2009. Pre-penetration stages of Guignardia psidii in guava: effect of temperature, wetness duration and fruit age. Journal of Phytopathology 157: 618-624.

Fischer, I.H.; Almeida, A.M.; Arruda, M.C.; Bertani, M.A.R.; Garcia, M.J.M.; Amorim, L. 2011. Postharvest damages in guavas from the Midwest region of the State of São Paulo. Bragantia 70: 570-576 (in Portuguese, with abstract in English).

Guerra, D.S.; Nickel, O.; Del Ponte, E.M.; Sanhueza, R.M.V.; Fajardo, T.V.M.; Marodin, G.A.B. 2012. Development of Glomerella leaf spot is enhanced in virus-infected maxi gala apples. Journal of Plant Pathology 94: 237-241.

Hughes, G.; Madden, L.V.; Munkvold, G.P. 1996. Cluster sampling for disease incidence data. Phytopathology 86: 132-137.

Lin, C.C.; Lai, C.S.; Tsai, S.F. 2003. Ecological survey of guava new fruit rot: Phyllosticta rot (black spot) and other fruit rots. Plant Protection Bulletin 45: 263-270.

Madden, L.V.; Hughes, G. 1995. Plant disease incidence: distributions, heterogeneity, and temporal analysis. Annual Review of Phytopathology 33: 529-564.

Martins, M.C.; Amorim, L.; Lourenço, S.A.; Gutierrez, A.S.D.; Watanabe, H.S. 2007. Incidence of post harvest damages in guavas at the wholesale market of São Paulo and its relationship to pre harvest bagging. Revista Brasileira de Fruticultura 29: 245-248 (in Portuguese, with abstract in English). 
Moraes, S.R.G.; Escanferla, M.E.; Massola Júnior, N.S. 2015. Prepenetration and penetration of Colletotrichum gloeosporioides into guava fruit (Psidium guajava L.): effects of temperature, wetness period and fruit age. Journal of Phytopathology 163: 149-159.

Northover, J.; Biggs, A.R. 1990. Susceptibility of immature and mature sweet and sour cherries to Monilinia fructicola. Plant Disease 74: 280-284.

Northover, J.; Cerkauskas, R.F. 1994. Detection and significance of symptomless latent infections of Monilia fruticola in plums. Canadian Journal of Plant Pathology 16: 30-36.

Paramasivan, M.; Ohan, S.; Li, G.S.; Mathiyazhagan, S.; Uthukrishanan, N. 2009. Detection of latent infections in mango fruit with herbicides. Archives of Phytopathology and Plant Protection 42: 318-326.

Paull, R.E. 1999. Effects of temperature and relative humidity on fresh commodity quality. Postharvest Biology and Technology 15: 263-277.

Piccinin, E.; Pascholati, S.F.; Di Piero, R.M. 2005. Guava diseases (Psidium guajava L. = Doenças da goiabeira (Psidium guajava L.). p. 401-405. In: Kimati, H.; Amorim, L.; Rezende, J.A.M.; Bergamin Filho, A.; Camargo, L.E.A., eds. Manual de fitopatologia: doenças das plantas cultivadas. 4ed. Ceres, São Paulo, SP, Brazil (in Portuguese).

Prusky, D.; Wattad, C.; Kobiler, I. 1996. Effect of ethylene on activation of lesion development from quiescent infections of Colletotrichum gloeosporioides in avocado fruits. Molecular Plant Microbe Interactions 9: 864-868.

Prusky, D.; Lichter, A. 2007. Activation of quiescent infections by postharvest pathogens during transition from the biotrophic to the necrotrophic stage. FEMS Microbiology Letters 268: 1-8.

Prusky, D.; Alkan, N.; Mengiste, T.; Fluhr, R. 2013. Quiescent and necrotrophic lifestyle choice during postharvest disease development. Annual Review of Phytopathology 51: 155-176.
Sharma, R.L.; Kaul, J.L. 1988. Susceptibility of apples to brown rot in relation to quantitative characters. Indian Phytopathology 43: 113-115.

Silva, C.F.B.; Michereff, S.J. 2013. Biology of Colletotrichum spp. and epidemiology of the anthracnose in tropical fruit trees. Revista Caatinga 26: 130-138.

Silva-Junior, G.J.; Spósito, M.B.; Marin, D.R.; Ribeiro-Junior, P.J.; Amorim, L. 2014. Spatiotemporal characterization of citrus postbloom fruit drop in Brazil and its relationship to pathogen dispersal. Plant Pathology 63: 519-529.

Singh, R.S. 2000. Diseases of Fruit Crops. Science Publishers, Enfield, NH, USA.

Soares-Colletti, A.R.; Fischer, I.H.; Lourenço, S.A. 2014. The incidence of postharvest diseases on 'Kumagai' and 'Pedro Sato' guavas at wholesale markets in Brazil. Tropical Plant Pathology 39: 478-482.

Spósito, M.B.; Bassanezi, R.B.; Amorim, L. 2004. Resistance to citrus black spot by the analyses of disease progress curves. Fitopatologia Brasileira 29: 532-537 (in Portuguese, with abstract in English).

Spósito, M.B.; Amorim, L.; Ribeiro, P.J.; Bassanezi, R.B.; Krainski, E.T. 2007. Spatial pattern of trees affected by black spot in citrus groves in Brazil. Plant Disease 91: 36-40.

Timmer, L.W.; Agostini, J.P.; Zitko, S.E.; Zulfiqar, M. 1994. Postbloom fruit drop of citrus, an increasingly prevalent disease of citrus in the Americas. Plant Disease 78: 329-334.

Valdebenito-Sanhueza, R.M.; Duarte, V.; Amorim, L.; Porto, M.D.M. 2005. Detection and epidemiology of white rot on apples. Fitopatologia Brasileira 30: 217-223 (in Portuguese, with abstract in English).

Wills, R.; McGlasson, B.; Graham, D.; Joyce, D. 2007. Postharvest: An Introduction to the Physiology and Handling of Fruits and Vegetables and Ornamentals. 5ed. CAB International, Wallingford, UK. 